\title{
The Digital Girls Response to Pandemic: Impacts of in Presence and Online Extracurricular Activities on Girls Future Academic Choices
}

\author{
Francesco Faenza ${ }^{1}$, Claudia Canali ${ }^{2}$ (D) , Michele Colajanni ${ }^{3}$ and Antonella Carbonaro $^{3, *(D)}$ \\ 1 Department of Economics Marco Biagi, University of Modena and Reggio Emilia, 41121 Modena, Italy; \\ francesco.faenza@unimore.it \\ 2 Department of Engineering Enzo Ferrari, University of Modena and Reggio Emilia, 41121 Modena, Italy; \\ claudia.canali@unimore.it \\ 3 Department of Computer Science and Engineering, University of Bologna, 40126 Bologna, Italy; \\ michele.colajanni@unibo.it \\ * Correspondence: antonella.carbonaro@unibo.it
}

check for

updates

Citation: Faenza, F.; Canali, C.; Colajanni, M.; Carbonaro, A. The Digital Girls Response to Pandemic: Impacts of in Presence and Online Extracurricular Activities on Girls Future Academic Choices. Educ. Sci. 2021, 11, 715. https://doi.org/ 10.3390/educsci11110715

Academic Editors: Andrea Burrows and Mike Borowczak

Received: 14 September 2021

Accepted: 2 November 2021

Published: 8 November 2021

Publisher's Note: MDPI stays neutral with regard to jurisdictional claims in published maps and institutional affiliations.

Copyright: (c) 2021 by the authors. Licensee MDPI, Basel, Switzerland. This article is an open access article distributed under the terms and conditions of the Creative Commons Attribution (CC BY) license (https:/ / creativecommons.org/licenses/by/ $4.0 /)$.

\begin{abstract}
In the last few years, several initiatives based on extracurricular activities have been organized in many countries around the world, with the aim to reduce the digital gender gap in STEM (Science, Technology, Engineering, Math) fields. Among them, the Digital Girls summer camp, organized every year since 2014 by two Italian universities with the aim to attract female students to ICT (Information and Communication Technologies) disciplines, represents quite a unique initiative for its characteristics of long-duration (3-4 entire weeks) and complete gratuitousness for the participants. The COVID-19 emergency imposed severe changes to such activities, that had to be modified and carried out in the online mode as a consequence of social distancing. However, on one hand, the general lack of high-quality evaluations of these initiatives hinders the possibility to understand the actual impact of extracurricular activities on the future academic choices of the participants. On the other hand, the availability of data collected over different editions of Digital Girls has allowed us to analyze the summer camp impact and to evaluate the pros and cons of in-presence and online activities. The main contribution of this paper is twofold. First, we present an overview of existing experiences, at the national (Italian) and international levels, to increase female participation in integrated STEM and ICT fields. Second, we analyze how summer camp participation can influence girls' future academic choices, with specific attention to ICT-related disciplines. In particular, the collection of a significant amount of data through anonymous surveys conducted before and after the camp activities over the two editions allowed us to evidence the different impacts of in-presence and online extracurricular activities.
\end{abstract}

Keywords: gender gap; ICT education; human capital; extracurricular STEM activities; in-presence and online education

\section{Introduction}

Developing relevant digital competencies and skills for the digital transformation is vital for Europe, to fully embrace the benefits of the digital revolution and remain competitive in the global market. In the future, indeed, nearly all jobs will require digital skills, but the European Commission figures show that two-fifths of the EU workforce have little or no digital skills [1]. The lack of digital competencies becomes even more evident if we consider the gender dimension. For example, in Italy, female ICT (Information and Communication Technologies) specialists comprise 1\% of all female employees (slightly below the EU average of 1.4\%) [2]. The underrepresentation of women in ICT professions begins at the university; according to Eurostat 2018 data [3], about 1.3 million people in Europe are enrolled in ICT courses (in different levels of education), but only 16.7\% of 
those who are enrolled are women (13\% in Italy). On average, in Europe, men graduate 5-7 times more frequently than women in ICT [4].

To counteract these trends, a plethora of initiatives and activities for teaching youngsters integrated STEM, ICT and other technology-related disciplines have been organized in the last few years in many countries around the world. However, the study in [5] points out the lack of data about the actual impact of all these summer camps. Such activities are usually carried out by practitioners and researchers without conducting high-quality evaluations of such programs, limiting the data collection to the number of participants and to a final questionnaire about the overall satisfaction. This situation hinders the possibility to understand whether these camps actually help to attract more women into STEM and ICT careers. There is also no data available to help understand which kind of approach or activity is more effective for achieving positive outcomes.

Among the existing initiatives, a particularly significant and innovative experience is represented by the summer camp 'Digital Girls'. The Digital Girls summer camp is organized every year by two Italian universities to attract high school female students to integrated STEM disciplines and reduce the digital gender gap. The proposed reallife application of STEM is naturally integrated, meaning that STEM is the purposeful integration of the various disciplines as used in solving real-world problems [6]. Offered completely free for the participants, since 2014 the summer camp has provided girls with a learning experience, based on a team-working and learn-by-doing approach, about coding applied to creative and innovative fields, such as video game programming or Arduino-controlled robot making, and with an exposure to inspiring female role models from academia and industry. The summer camp is dedicated to students of the third and fourth grades of the high schools and no previous competencies are required in terms of coding or ICT skills. During the camp, which lasts four entire weeks, girls learn coding as applied to creative and innovative fields, such as video game programming or Arduinocontrolled robot making and are exposed to inspiring female role models from academia and industry. In 2020, the COVID-19 pandemic and the consequent social distancing measures hindered the possibility to carry out the Digital Girls summer camp in presence: the 2020 camp was carried out completely online and changes were required in the types of activities and in terms of duration (reduced to three weeks). It is worth noting that the Digital Girls project has been recognized as a best practice to reduce the gender gap in ICT disciplines in the context of the Horizon 2020 Project EQUAL-IST "Gender Equality Plans for Information Sciences and Technology Research Institutions" [7] and of the Erasmus+ project Gender4STEM "Gender aware education and teaching".

The contribution of this paper is twofold. First, we provide an overview of existing experiences at the national (Italian) and international level that aim to increase female participation in STEM and ICT, thereby highlighting how, at the national and European level, Digital Girls represents a unique experience in its nature of being free, long-lasting and specifically dedicated to girls. At the international level, very few camps appear to have similar characteristics as most of the initiatives are hosted by a private Organisation, last more or less a week and are quite expensive for the participants.

Second, we present an analysis of the impact of the summer camp on the participants, comparing in-presence and online editions. To this end, data were collected through the submission of anonymous surveys before and after the summer camp activities. In this paper, we present an analysis of the survey results, focusing on several aspects, ranging from the participants' satisfaction to their perception about computer science in terms of awareness and appreciation. Furthermore, we show how participation in the summer camp may affect the girls' intention to continue their studies in ICT-related disciplines or in other fields.

The rest of this paper is organized as follows. Section 2 describes the theoretical framework in relation to the situation of the gender digital divide and presents an overview of the existing experiences to increase women's participation in ICT and STEM disciplines. Section 3 describes the Digital Girls Summer Camp as a best practice to counteract the 
gender gap in ICT, providing information on the project regarding the type of users, the type of activities carried out, the profiles of the girls involved, the methodology and the type of activities carried out. Section 4 evaluates the impact of the summer camp on the participants, highlighting differences between in-presence and online editions. Section 5 concludes the paper with some final remarks.

\section{Overview of Initiatives to Promote Female Participation in STEM and ICT}

The COVID-19 crisis has shown that adequate digital skills empowering citizens to access information and services are crucial for the whole population. In Italy, only $42 \%$ of people aged 16-74 years have at least basic digital skills (58\% in the EU) and only $22 \%$ have above basic digital skills (33\% in the EU). Furthermore, only $1 \%$ of Italian graduates are ICT graduates (the lowest in the EU).

The digital gap, in Europe as well as in Italy, becomes even more evident if we consider the gender dimension. According to an Organisation for Economic Cooperation and Development [8] analysis on the Programme for International Students Assessment PISA 2015 data about 15 years old students' expectations about their future, boys are more likely than girls to see themselves as working in ICT; on average $0.4 \%$ of girls and $4.8 \%$ of boys have the expectation to become employed as ICT professionals. According to Eurostat 2018 data [3], about 1.3 million people in Europe are enrolled in ICT courses (at different levels of education), but only $16.7 \%$ are women (13\% in Italy). Moreover, a focus on tertiary education allows us to see that in 2015, amongst graduates in Europe, only 3.6\% graduated in ICT, and only 19\% of them were women, therefore [4] men graduate at a rate of 5-7 times more than women in ICT on average in Europe. In Italy, female ICT specialists comprise $1 \%$ of all female employees (slightly below the EU average of $1.4 \%$ ) [2].

One of the main reasons for the observed gender gap appears to be related to cultural issues, including gender stereotypes in ICT fields: a phenomenon known as the "stereotype threat", meaning that gender stereotypes have negative consequences for girls' performance and interest in ICT and technological fields [9]. The problem is related to the perception of subjects of study and professions as masculine or feminine: ICT disciplines are perceived as masculine by the students, differently from many other academic disciplines and even from some STEM disciplines, such as mathematics. Another issue is represented by the lack of computer science disciplines in the Italian primary and secondary schools, the lack of knowledge regarding what computer science and ICT actually are, is likely to reinforce the stereotype about masculine disciplines among the younger generations [10]. OECD studies claim that girls' late exposure to computers can be associated with nonmaterial barriers in the access to digital learning. These observations are confirmed by other results in the literature about gender gaps in STEM and ICT studies. Girls may show lower motivation than boys for computer science because they have fewer experiences with technology, and this negatively affects their interest and self-confidence in these fields [11]. Another important element that contributes to the digital gender gap is the lack of female role models in technological fields, which reinforces gender stereotypes. An interesting study [12] showed that role model exposure had positive effects on both STEM and non-STEM students' interest in STEM disciplines.

The European Commission suggests that this gender gap should be addressed by a set of policies that include breaking gender stereotypes by means of awareness-raising campaigns and concrete actions [9]. To prevent the observed segregation by gender in Tertiary education, these stereotypes must be addressed by means of earlier interventions in a student's life, including awareness-raising campaigns and training $[13,14]$.

Given the well-known gender gap in the ICT and STEM fields [2,4], and the potential social and economic consequences of the phenomena [1], many international organizations have highlighted the need for countermeasures and have suggested active policies to counteract stereotypes regarding women in these fields. The monitoring of education systems and the creation of ad-hoc events are among the suggested actions. 
Many initiatives to tackle the gender gap have been implemented in the recent years, and this paper aims to analyze the main actions taken in relation to ICT and STEM education. Although these kinds of initiatives are usually documented and advertised online, it may prove challenging to find reliable and complete information about all of them. Hence, the results presented in this paper represent an (possibly non-exhaustive) overview of the main initiatives realized in Italy and in other countries, which are summarized in Table 1.

Table 1. Italian STEM/ICT initiatives.

\begin{tabular}{|c|c|c|c|c|c|c|c|}
\hline Name & City & Target Age & $\begin{array}{l}\text { Hours of } \\
\text { Activity }\end{array}$ & $\begin{array}{c}\text { Cost Per } \\
\text { Participant }\end{array}$ & $\begin{array}{c}\text { Gender } \\
\text { Quota }\end{array}$ & Organizer(s) & Last Edition \\
\hline GCIB & $\begin{array}{l}\text { Multiple } \\
\text { cities }\end{array}$ & $11-18$ & 45 & free & female only & MAW & 2021 \\
\hline Django Girls & $\begin{array}{l}\text { Multiple } \\
\text { cities }\end{array}$ & $\begin{array}{c}\text { no age } \\
\text { limitation }\end{array}$ & 8 & free & female only & $\begin{array}{l}\text { Python } \\
\text { Foundation, } \\
\text { Django } \\
\text { Foundation }\end{array}$ & 2021 \\
\hline NERD? & $\begin{array}{l}\text { Multiple } \\
\text { cities }\end{array}$ & $16-19$ & $10 / 20$ & free & female only & IBM & 2021 \\
\hline $\begin{array}{l}\text { Makers } \\
\text { Camp }\end{array}$ & Milan & $8-18$ & $20 *$ & $180 €-240 €$ & no & $\begin{array}{l}\text { municipality, } \\
\text { university }\end{array}$ & 2018 \\
\hline H-Farm & Venice & $5-18$ & $30 *$ & $499 € /$ week & no & private & 2021 \\
\hline Nuvola Rosa & Milan, Venice & $17-24$ & $80 *$ & free & female only & $\begin{array}{c}\text { private, } \\
\text { municipality }\end{array}$ & 2017 \\
\hline Archicamp & Varese & $6-14$ & $30 *$ & $15 €$ & no & municipality & 2019 \\
\hline $\begin{array}{l}\text { Capriolo } \\
\text { Factory }\end{array}$ & Florence & $12-16$ & $30 *$ & $365 €-400 €$ & no & private & 2021 \\
\hline Il_Laboratorio & FLorence & $7-99$ & $15-20$ & $100 €-135 €$ & no & university & 2021 \\
\hline STEM@IT & Pescara & $7-16$ & $20-80$ & $225 €-595 €$ & no & private & 2021 \\
\hline $\begin{array}{c}\text { TechCamp@ } \\
\text { POLIMI }\end{array}$ & Milan & $14-19$ & 27 & $700 €$ & no & university & 2021 \\
\hline $\begin{array}{c}\text { Campus } \\
\text { STEM }\end{array}$ & Florence & $8+$ & 15 & $140 €$ & no & university & 2020 \\
\hline ELLESSE & L'Aquila & $7-16$ & $12-24$ & $740 €-1320 €$ & no & private & 2021 \\
\hline $\begin{array}{l}\text { Champions } \\
\text { Camp }\end{array}$ & Andalo & $8-13$ & $25 *$ & $550 €-950 €$ & no & private & 2021 \\
\hline Phygital & online & $5-15$ & 30 & $199 €$ & $60 \%$ female & private & 2021 \\
\hline $\begin{array}{l}\text { Digitus Lab } \\
\text { Camp }\end{array}$ & Milan & $8-14$ & 25 & $206 €$ & no & private & 2021 \\
\hline ToScienceCamp & Cuneo & $12-14$ & * & $190 €-440 €$ & no & private & 2020 \\
\hline ROBOCAMP & Milan & $10-14$ & 12 & $410 €$ & no & private & 2020 \\
\hline
\end{tabular}

* Not clear or missing information.

In order to better understand the possible typologies of initiatives, it could be useful to distinguish between awareness-raising initiatives, such as isolated workshops or seminars, and extracurricular activities. The latter categories could be further divided into activities that are distributed over a long period of time (e.g., school year) and summer camps, which are typically intensive and immersive activities that take place across quite short timeframe (few days/weeks).

In Italy, Girls Code It Better, NERD? and Django Girls are examples of extracurricular projects, that are entirely dedicated to girls, and that allow girls to experience ICT and related subjects. In most European nations as well as in the US, Canada and the UK, there are equivalent initiatives; Django girls, for example, has a widespread community across the globe (including Africa, Oceania, and Asia). These three initiatives are not classified as summer camps and significantly differ from Digital Girls. Django Girls is a non-profit Organisation and a community that empowers and helps women to organize free, one- 
day programming workshops for women, and does not impose age restrictions. These workshops can be classified as awareness-raising initiatives where participants learn the basics of Web development with Python and Django. Girls Code It Better (GCIB) is an extracurricular activity mainly directed at middle schools, whereby a school participating in the initiative follows a common format provided by GCIB central organization and carries out afternoon sessions for voluntary female students. The course is held by an external expert, chosen and trained by the GCIB central Organisation, supported by an internal tutor, and is distributed over the scholastic year. Finally, the NERD? (Non è Roba per Donne?) project, developed in 2013 by IBM Foundation Italy in collaboration with the University of Rome IT Department, hosts a few sessions each year, and workshops in which girls from high school can learn mobile app programming. The initiative now involves almost 16 universities throughout Italy.

The other initiatives included in Table 1 are summer camps. However, it is worth noting that the table does not include curricular activities that individual schools integrate into their study plan, such as projects funded by the Italian Ministry of Education through the PON (https:/ / poninchiaro.istruzione.it/poninchiaro/?lang=en, accessed on 31 October 2021) (National Operational Programme) program or the Coding Girls project, an international format that consists of a series of events autonomously and locally organized by schools, leading to a final hackathon, in which usually around 100 girls participate. These initiatives certainly testify to the emerging initiatives that respond to the need to increase the skills of the young generations in the ICT sector, however, they are not included in our analysis due to their completely different nature with respect to Digital Girls.

Returning to Table 1, we observe that there are very few summer camps entirely or even partially dedicated to girls that are currently active, potentially highlighting a lack of knowledge or interest in the gender gap in STEM and ICT.

For the initiatives reported in Table 1, most of the camp organizers are private companies and associations, and very few are offered as either free or almost free. Nuvola Rosa was identified as one of the free camps for females only, but it seems to be no longer active; since no recent information is available and the hosting site is now offline, most of the information about the initiative is taken from newspaper articles and internet archives.

As we can observe from the last column of Table 1 (year of the last edition), many summer camps have been suspended or reorganized to be accessible from home due to the COVID-19 pandemic. With regard to the duration and cost per participant, the majority of the initiatives have a duration of one week with a cost ranging between $140 €$ and $1320 €$, except for those that are financed by municipalities or big tech companies.

Moving the analysis to the international level, the situation is harder to depict. In fact, while it is relatively easy to find international initiatives related to English-speaking nations, it is much harder to find initiatives of countries like France, Germany, Spain and other non-English speaking countries. Considering that many summer camps are generally oriented to girls and boys of their local communities, it is not easy to obtain information or details about them.

Table 2 reports the most prominent summer camps that have been established in other countries as indexed by Web search engines; given the abundance of worldwide initiatives oriented to STEM and ICT, only those specifically designed for girls have been included in this table, which presents the same columns considered for the Italian case.

As in the case of Italy, almost all of the camps have been reorganized for distance learning due to the COVID-19 pandemic, and by looking at the organizers, the duration of the activities and the cost, the majority of the camps are found to be hosted by a private organisation, last more or less than a week and are quite expensive for the participants. 
Table 2. International STEM camps.

\begin{tabular}{|c|c|c|c|c|c|c|c|}
\hline Name & Country/City & Target Age & $\begin{array}{c}\text { Hours of } \\
\text { Activity }\end{array}$ & $\begin{array}{c}\text { Cost Per } \\
\text { Participant }\end{array}$ & $\begin{array}{l}\text { Gender } \\
\text { Quota }\end{array}$ & Organizer(s) & Last Edition \\
\hline Technovation & global & $10-18$ & $20+$ & free & female only & private & 2021 \\
\hline GirlsSpark & Hong Kong & $\begin{array}{l}\text { university } \\
\text { students }\end{array}$ & 24 & free & female only & private & 2018 \\
\hline $\begin{array}{l}\text { Girls Who } \\
\text { Code }\end{array}$ & USA & $\begin{array}{l}\text { high school } \\
\text { students }\end{array}$ & 210 & free & female only & no-profit & 2021 \\
\hline $\begin{array}{c}\text { MIT } \\
\text { WTP-EECS }\end{array}$ & USA & $\begin{array}{l}\text { high school } \\
\text { students }\end{array}$ & 120 & $3500 \$$ & female only & university & 2021 \\
\hline Alexa Cafè & $\begin{array}{c}\text { Hong Kong, } \\
\text { USA }\end{array}$ & $10-15$ & 36 & $950 \$ * *$ & female only & private & 2021 \\
\hline $\begin{array}{l}\text { Black Girls } \\
\text { Code }\end{array}$ & USA & $12-17$ & * & $699 \$ * *$ & female only & foundation & 2021 \\
\hline $\begin{array}{l}\text { Kode with } \\
\text { Klossy }\end{array}$ & USA & $13-18$ & $72 *$ & free & female only & $\begin{array}{c}\text { charitable } \\
\text { organization }\end{array}$ & 2021 * \\
\hline SciGirls & USA & $11-15$ & 30 & $200 \$$ & female only & organization & 2021 \\
\hline $\begin{array}{l}\text { Summer } \\
\text { STEM LAB }\end{array}$ & online & $4-12$ & 15/week & $325 \$$ & female only & organization & 2021 \\
\hline GSTEM & USA & & 5/week & $4000 \$$ ** & female only & private & 2021 \\
\hline $\begin{array}{l}\text { Scientific and } \\
\text { technical } \\
\text { camps }\end{array}$ & France & 13-15 & 24 & $*$ & female only & university & 2021 \\
\hline $\begin{array}{l}\text { Robotic } \\
\text { institute }\end{array}$ & Germany & $14-16$ & $40-80$ & $800 €-1600 €$ & female only & university & 2021 \\
\hline
\end{tabular}

${ }^{*}$ Not clear or missing information. ${ }^{* *}$ Scholarships may apply.

Two specific initiatives deserve to be mentioned: Girls Who Code and Kode with Klossy. Founded by female role models, both projects have a significant number of hours of activities at $210 \mathrm{~h}$ and $72 \mathrm{~h}$ respectively and given the fact that they are free to participants, are substantially different with respect to the other listed initiatives and share more similarities with the Digital Girls camp. However, we did not find related results analyzing the effectiveness of the activities after being adapted as a consequence of the pandemic.

Initiatives within Scandinavian countries are also worth considering. Table 2 does not include any Scandinavian initiatives; however, a report by Norway Plan International [15], investigating the gender gap in technology in Sweden, Norway and Denmark, highlights that, although Scandinavian countries are better placed than other European countries with regards to gender equality policies, they are not exempt from the gap in technology, with an average share of $30-35 \%$ of female STEM graduates. The study also reported that IT camp initiatives carried out in the past years helped increase the percentage of female students admitted to the bachelor's degree in software development.

\section{The Digital Girls as a Best Practice to Counteract Gender Gap in ICT}

The first summer camp, Digital Girls, was designed and organized by the Department of Engineering 'Enzo Ferrari' of the University of Modena and Reggio Emilia in collaboration with the association of European Women Management and Development (EWMD) in 2014 in the city of Modena. Year after year, the summer camp experienced a continuous increase in the number of girls participating in the initiative, and in 2018 the camp was replicated in other cities of the Emilia Romagna Italian region. In particular, a camp was launched in the nearby city of Reggio Emilia followed by another in the city of Cesena, organized by the Department of Computer Science and Engineering of the University of Bologna.

All the editions of the summer camps Digital Girls [16,17] are characterised by a long duration, lasting 3 or 4 weeks and engage the participating girls in laboratory activities based on a learning-by-doing and project-based approach with a two-fold aim: (1) to 
smoothly and positively introduce girls to computer science and a "smart" technological world; (2) to give girls a better understanding of what ICT is and how it can be applied to innovative and multidisciplinary fields. More specifically, the activities were based on video games programming in the Python language and on Arduino-controlled robot making. In the last 2 weeks of the summer camp, girls worked in smaller teams of 6-7 girls, each one developing its own project. Besides acquiring basic coding competencies, this approach allowed girls to develop soft skills such as communication, teamwork and problem-solving. On the last day of the summer camp, an event was organized during which representatives from each team presented the developed projects. Furthermore, dedicated seminars consisting of speeches by external experts and women who have reached leadership positions because of scientific studies, were organized during the summer camps with the goal to promote existing female role models. The aim of such seminars was to expose girls to examples that disrupt the well-known social gender stereotypes and to present the concrete opportunities that ICT-related competencies may offer in terms of studies and careers at the local and national levels.

In 2020, the COVID-19 pandemic and the consequent social distancing measures led to the impossibility of holding the Digital Girls summer camp in-person. The 2020 editions were organized to be held completely online and some adaptations were required in terms of their duration and the available activities. A three weeks camp, based on a learn-by-doing approach, was realized for the online edition organized by Modena and Reggio Emilia, while the Cesena camp lasted for two weeks and mainly provided speeches and seminars on computer science topics.

The 2020, Modena-Reggio Emilia online edition was organized with three weeks of activities, including daily meetings that lasted three hours from Monday to Thursday. The girls were divided into two groups that focused on programming activities concerning the following application fields: Web sites development and game programming with Python. Even though the online nature of the summer camp theoretically facilitates the participation of a greater number of girls with respect to the past editions, the choice of a team-based approach and the consequent requirements in terms of teachers/tutors actually limited the overall participation to a total of 75 girls.

The 2020, the Cesena online edition was organized with daily meetings of $2 \mathrm{~h}$ on different topics of computer science. The different topics were explored by inviting female and male speakers. Speeches were organized on the following topics: open source software, informatics and 3D cell cultures, quantum computing, the problem-solving approach as a key element of professionalism, biometrics and computer science in primary schools. The seminary-based approach allowed a greater number of girls to participate in the activities.

From the comparison with the initiatives described in Section 2, we can state that the summer camp Digital Girls is an innovative project, and both its duration and the fact that it is free for the participants make this initiative unique.

\section{Impact Evaluation}

In this section, we present the impact evaluation carried out on the data collected over the 2019 and 2020 editions of the summer camp. In the rest of this section, we first present the methodology followed for the data collection and analysis. Then, we describe the obtained results, analyzing the impacts under several points of view, and we conclude with a final discussion.

\subsection{Materials and Methods}

During each edition of the summer camp, we collected data from the participants by submitting two surveys, one before and one after the camp. Surveys were submitted during the camp's hours in the form of anonymous online forms. The questionnaire submitted before the camp (hereafter before camp questionnaire) consists of 30 questions that can be divided into three main categories, which are personal background, personal choices (including questions related to future choices in terms of studies and career) and 
computer science perception. Questions can be further classified based on the typology of answers, such as long and short free-text, numerical input, single-choice, multiplechoice and Likert scale choice. The same categorization and typology of questions appear in the questionnaire submitted at the end of the camp activities (hereafter after camp questionnaire); some questions are repeated to evaluate the change in the girls' answers, and additional questions, specific to camp satisfaction and impact, were included, for a total of 35 questions.

The analysis sought to develop an understanding of whether different editions of the summer camp (in-presence vs online, learn-by-doing vs seminary-based experience) may have different impacts on the participating girls. To this aim, our evaluation considers the last two years of the summer camp: the 2019 in-person edition, with 107 participants at the camp in Modena-Reggio Emilia (hereafter MO-RE) and 50 in Cesena (all editions based on a learn-by-doing approach) and the 2020 online edition, with 75 girls in MO-RE (learn-bydoing approach) and 160 girls in Cesena (seminary-based approach). More specifically, the analysis reported in this paper focuses on the girls' overall satisfaction, their perception about computer science in terms of awareness and appreciation, and their intentions regarding future academic/career choices. Finally, we investigate which aspects were more appreciated over the summer camp editions. The specific questions used in the survey and the methods to process the girls' answers are detailed in the following subsection.

\subsection{Results}

The Digital Girls summer camp satisfaction represents an essential aspect of the analysis. In both of the editions considered in this analysis, participants were asked to answer the question: "How do you evaluate your overall satisfaction about the camp experience?". For this question we used a Likert 5-point scale with answers ranging from 1 (very dissatisfied) to 5 (very satisfied).

In Figure 1, we report the results for the 2019 in-presence edition (left side) and for the 2020 online edition (right side). For each edition, we consider the average satisfaction expressed by the participants at each single camp (MO-RE and Cesena), which is represented through vertical bars, and the average overall satisfaction for each edition, represented with the horizontal dotted lines. While the satisfaction for MO-RE and Cesena camps are almost identical in the 2020 edition, we observe a difference in the results of the 2019 edition. The difference can be explained by the high level of experience of the MO-RE camp's teachers, as in 2019 the MO-RE camp was at its sixth edition, while the Cesena camp was only at its second edition and there was a significant turn-over among the teachers. However, we see that the overall edition averages, represented by the dotted lines, do not change significantly between the in-presence and online edition, as shown in Figure 1.

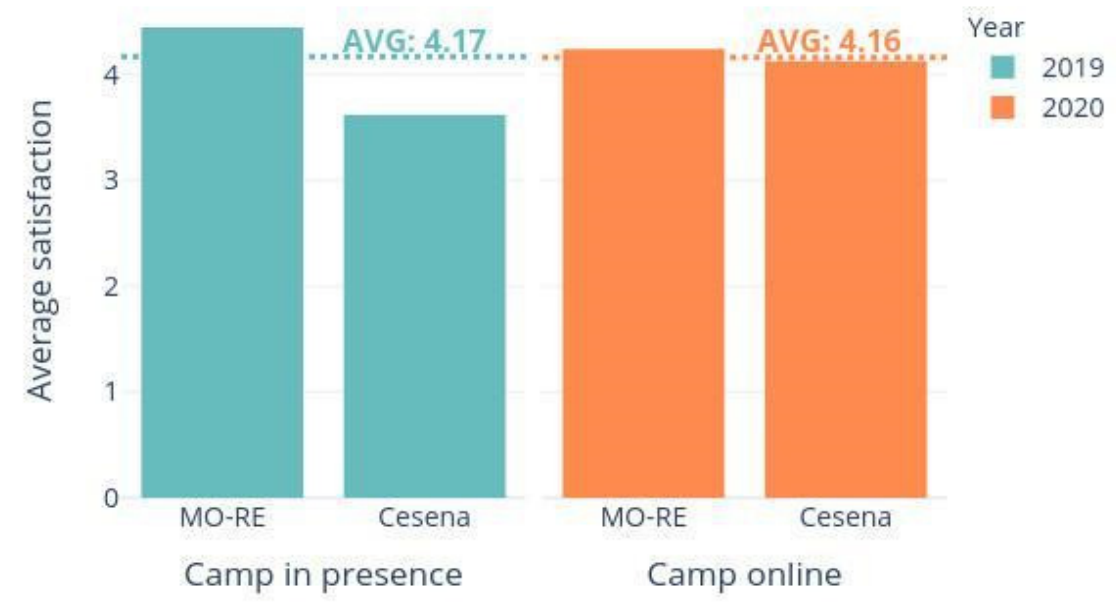

Figure 1. Average Summer Camp Satisfaction (1-5 range). 
The results are quite surprising as, we expected a less enthusiastic and positive perception of the online edition of the summer camps due to the long period of online lessons and social distancing caused by the COVID-19 pandemic. Moreover, both the MORE and Cesena online camps in 2020 obtained high satisfaction levels, meaning that girls appreciated both a learn-by-doing teamwork experience and a seminary-based approach.

We now focus our evaluation on one of the camp's main objectives, that is, to increase awareness and improve perception about ICT and computer science (CS) disciplines. Two specific questions were included in the survey to this end, one regarding CS awareness, aimed at understanding whether the participants acquired a more precise idea of what CS is; the other on CS appreciation, investigating whether the personal perception of CS improved after attending the summer camp.

For CS awareness, we asked girls: "How much did you clear your mind about computer science?" with the possibility to answer with: "Not at all", "Slightly", "Moderately", "Very", "Extremely"; for the aspect of CS appreciation we asked: "What is your idea about computer science after the camp?" giving as possible answers: "I like it much less than before", "I like it less than before", "Unchanged", "I like it more than before", "I like it much more than before". For both answers, we converted the choice to a Likert 5-point scale. The results show an average rating of 3.79 (out of 5) points for CS awareness and 4.02 (out of 5) points for CS appreciation, with no significant differences between in-presence vs online editions, or between online learn-by-doing vs a seminary-based approach.

As already stated, the awareness objective is strictly related to the general aim to introduce girls to computer science to help them make a more informed choice about their future studies and to hopefully reduce the gender gap in ICT fields. The approach used to design the summer camp activities encourages practice and interaction by focusing on individual learning and experimentation, with the specific aim to attract girls to computer science. To evaluate such a critical impact of the camp, we tried to measure the change in the intentions about future study choices as a consequence of participation in the activities provided by Digital Girls. We included two specific questions in the surveys submitted before and after the camp: (1) "Do you intend to continue your studies at the university?", and in case of a positive answer (2) "In which field do you intend to continue your studies?". For the second question, we allow multiple choices, which we converted to the International Standard Classification of Education (ISCED) [18], including the option related to the F06 field-Information and Communication Technologies.

We first evaluated the answers provided in the before camp questionnaire. We obtained similar results between the 2019 and 2020 editions; hence, for reasons related to space, we report only the data about the 2019 summer camp (shown in Figure 2).
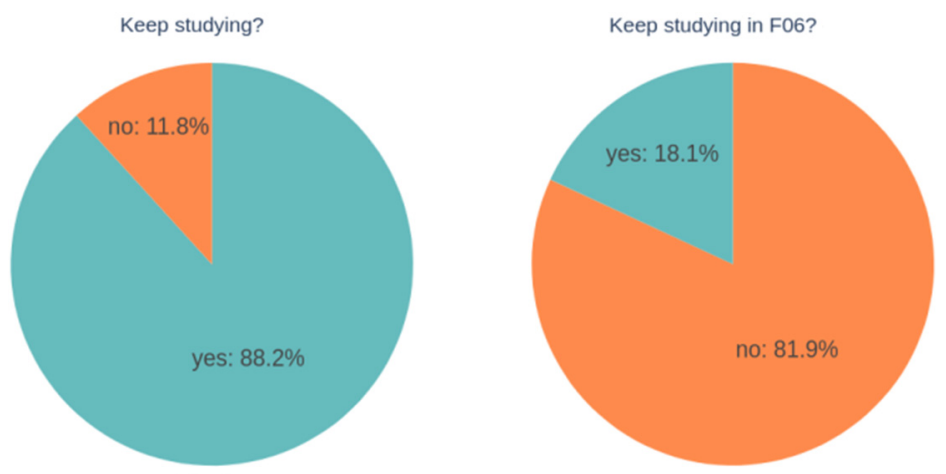

Figure 2. Future academic choices emerged before the camp.

From the left side of Figure 2, we observe that almost $88 \%$ of girls express the intention to continue their studies after high school, in any field of study, while the percentage of girls with the intention to continue in F06, that is the ICT field, is around 18\% (right part of the figure). We note that this percentage is much higher than the average percentage of women enrolled in F06 studies at the European level. In fact, as shown by Eurostat data [19] 
on students' enrollment in tertiary education, 10.560 .208 women are enrolled in tertiary education in Europe (EU28), but only 182.631 are enrolled in the ICT field (corresponding to $1.7 \%$ ). Our results are very surprising, considering the European scenario, but they can be explained by the fact that the Digital Girls summer camp is likely to attract a higher percentage of girls interested in continuing their studies in ICT disciplines compared to the average of girls of the same age. Moreover, we should consider here that girls express an intention, while the Eurostat data reports the effective percentage of female students enrolled in the F06 field.

To better understand the summer camp's impact, we decided to evaluate the connection between their choice of the academic studies and their previous experience in coding, if any, which may have been acquired during their education. From the before camp questionnaire, we know that only $26.2 \%$ of the participants had already tried coding before attending the summer camp. Hence, we analyzed the difference in the university choices, considering the data clustered on previous coding experience. The results are shown in Figure 3.
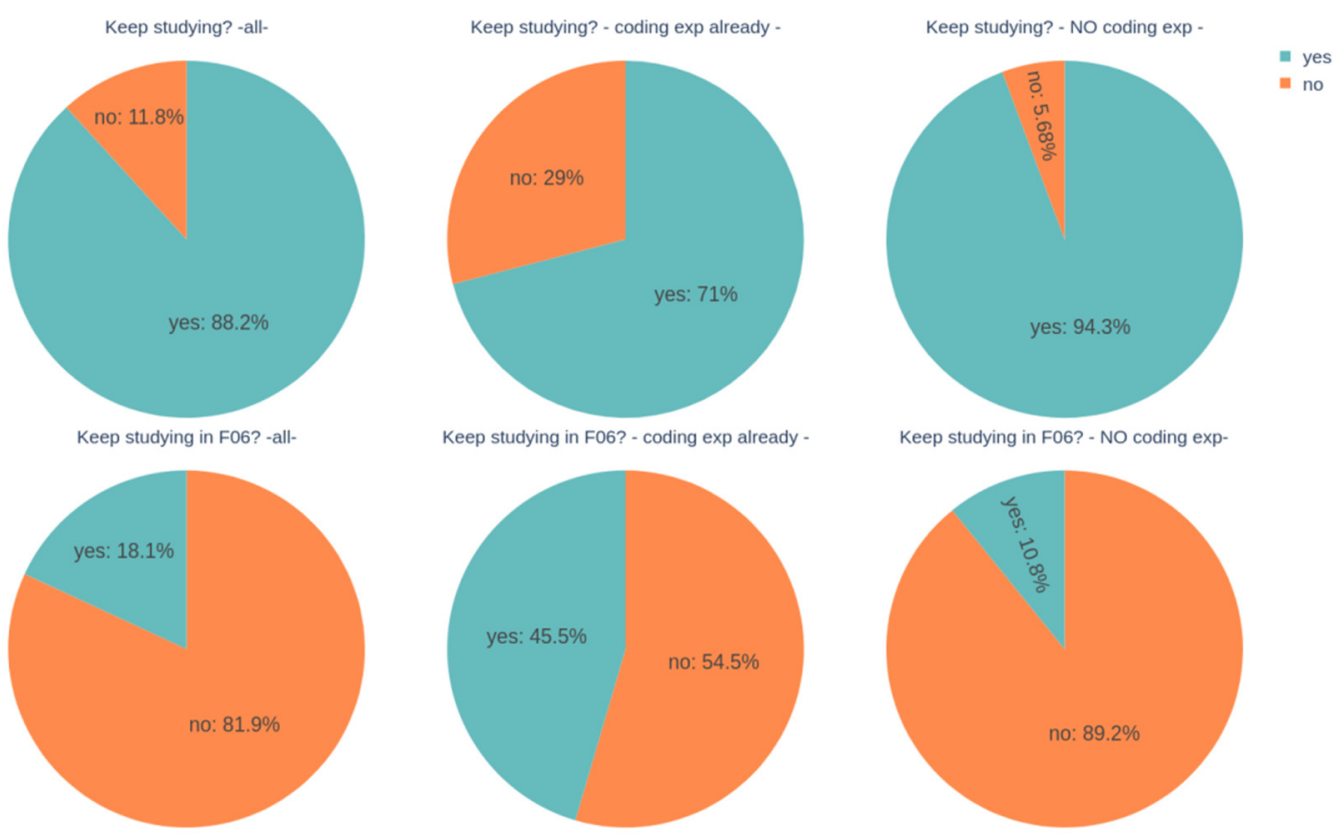

Figure 3. Future academic choices, disaggregated based on previous coding experience, as emerged before the camp.

Figure 3 outlines a significant difference between the girls who have already experienced coding and their peers without the same experience. On the one hand, a higher percentage of girls with previous coding experience express the intention of not continuing their studies: this can be explained by the fact that they are aware of having a skill, that is highly appreciated and valued in the current job market, which allows them to easily find employment. On the other hand, among the girls aiming to continue their studies, it is evident that those who have already experienced coding are much more likely to continue their studies in the F06 ICT sector than their peers (45.5\% vs. $10.8 \%)$. This result is very significant as it highlights the importance of experiencing coding at school and how such an experience may positively and significantly impact students' willingness to choose F06 as a field study as a woman.

Let us now evaluate the impact of the summer camp on the girls' future choice of studying in an ICT field. To this end, we compare the girls' answers before and after the summer camp experience. Furthermore, we compare the data obtained in 2019 and 2020 to understand any potential different impacts between in-presence and online editions of Digital Girls. 
Figure 4 compares the answers provided before (left part of the graph) and after (right part of the graph) the in-presence summer camp in 2019: the results show that the percentage of girls motivated to continue studies in F06 ICT fields increases from $18.1 \%$ to $25.9 \%$. The results show that the summer camp experience carried out in-presence appears to positively affect the girls' willingness to choose a computer science discipline.
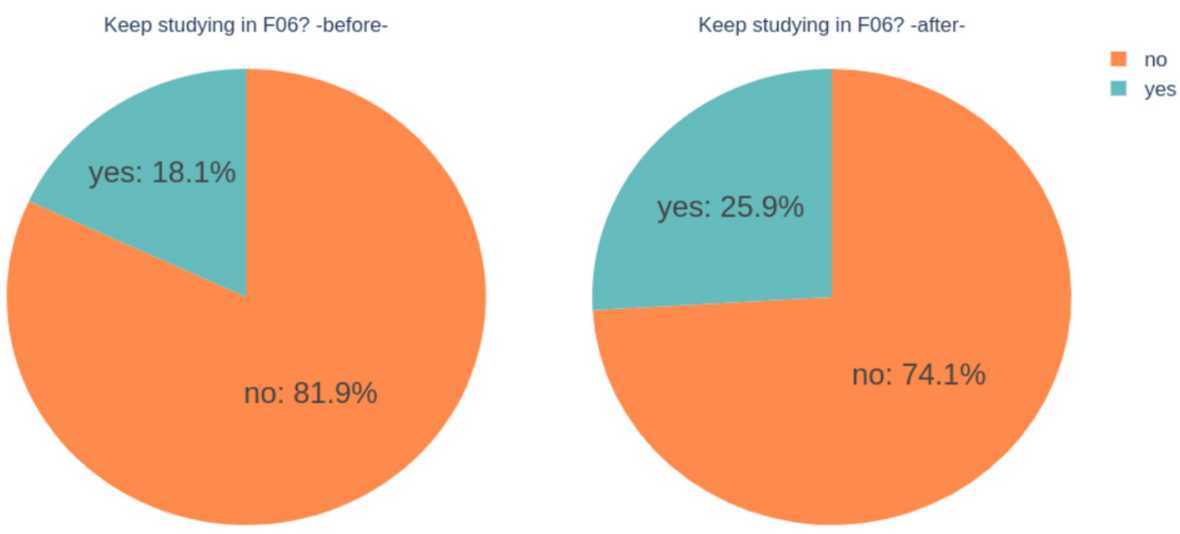

Figure 4. Data about 2019 summer camp (in-presence).

A fascinating result emerges when comparing 2019 in-presence and 2020 online results, represented in Figure 5, such that we observe a similar increment.
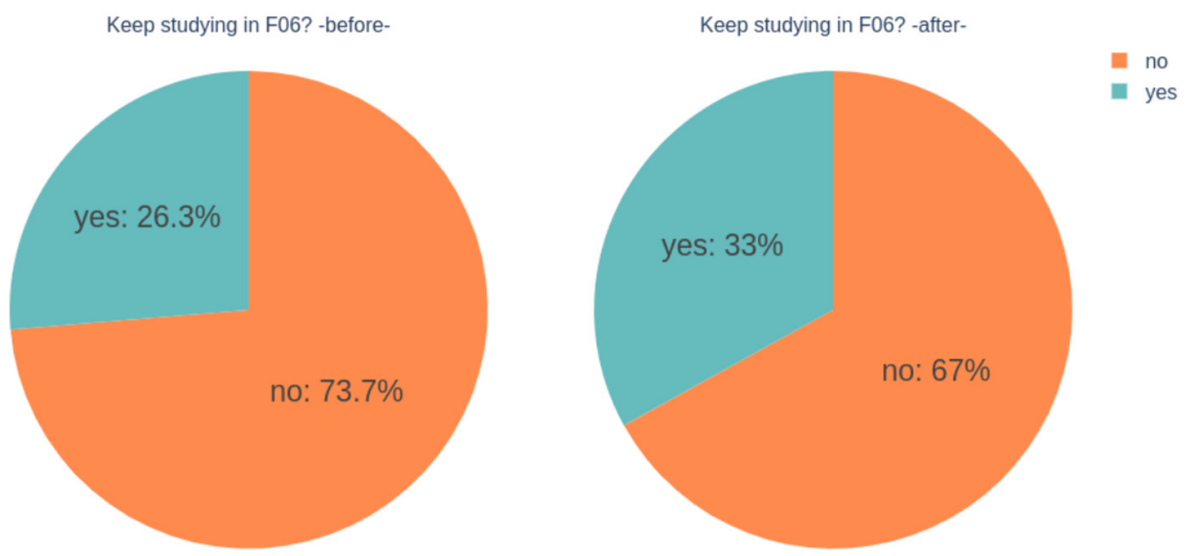

Figure 5. Data about summer camps 2020 (online).

We note a higher percentage of girls choosing an ICT field in the before camp questionnaire in 2020 compared to 2019. The outcome could be motivated by the higher presence of girls with previous programming experience; moreover, we suppose that the online edition of the summer camp may attract highly motivated girls. In fact, the selection of extracurricular online activities is typically broader and, the effect of joining friends in the same classroom/school to share an in-presence experience is missing. On the other hand, the percentage of girls willing to continue studying in F06 fields that emerged from the 2020 after camp questionnaire do not significantly differ from what we observed for the 2019 edition. The summer camp experience seems to have a positive impact on the participants' future choices, both for the in-presence and online editions.

Finally, to further investigate the difference among the camp editions, we analyze the answers to two free-text questions: (a) "describe what you liked more about the camp"; (b) "describe what you liked more about your project". Specifically, one or more significant tags were assigned to each answer to characterize it. For example, the answer "I liked to work in a team" has been tagged with the single tag "teamwork", while the answer "I liked the collaboration within my group and teacher's friendliness" has been tagged with 
the following tags: "teamwork" and "teaching_style". Then, the occurrences of tags were counted to identify the main trends. Figure 6 shows the percentage of the tag occurrences during the two considered editions of 2019 (in presence) and 2020 (online). A missing column for a tag means zero occurrences of that specific tag. One of the main observations is the absence of the tag "friendship" in the comments about the 2020 online edition: this tag was assigned to all comments that included the experience of getting to know someone else, which were included in the 2019 edition's comments, in statements such as "I liked to meet new people" or "I liked to interact with new people and make new friends". The absence of this tag evidences the missing social interaction among girls and the difficulty to establish relationships and new friendships during online activities.

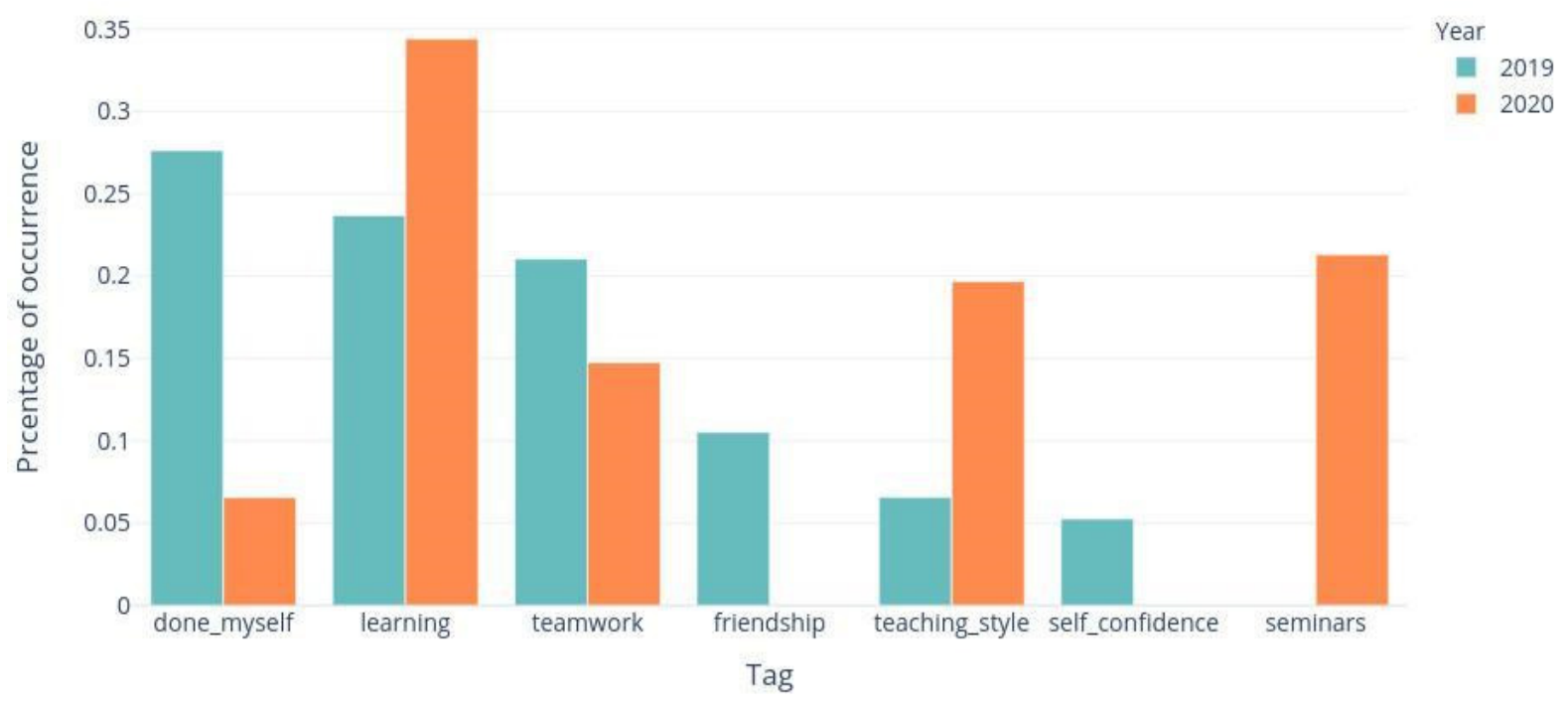

Figure 6. Tags analysis.

Moreover, we observe that the frequency of the tag "teamwork" slightly decreased for the online edition in comparison to the in-presence edition, stressing the increased difficulty of collaborating and interacting with other participants during the project development phase. We also note that the tag "seminars" is only present in the 2020 online edition: this is motivated by the fact that, when engaged in laboratory activities and in the implementation of a complex project (as in the in-presence edition), girls express less appreciation for seminars, because they feel the urge to finalize their projects.

A very interesting observation about the tag "self-confidence" emerged that is absent from the online edition: in-presence activities appear to be more effective in increasing the girls' self-confidence in computer science. The same concept emerges with the tag "done-myself", which is much more present in the results related to the in-presence edition. These observations reveal how a fundamental element to counteract the gender gap $[20,21]$ is more likely to be achieved by means of in-presence laboratory activities. Female students are usually much less confident in their computer skills than male students. Hence, improving girls' self-confidence in ICT fields may comprise a key element to engage more women in computer science [22-25].

\subsection{Discussion}

If we want to strengthen girls' integrated STEM capabilities and development, we need to do so in a way that does not increase or reproduce the patterns of inequality and exclusion that our societies are trying to overcome. Generally, we require more data on the main variables influencing the digital divide, and a closer analysis of its relationship with social class, age and ethnicity [26]. However, we have a clearer picture when it comes to gender. For example, the Commission's 2018 study "Women in the Digital Age" pointed out that only 24 out of 1000 female graduates studied an ICT-related subject and only six 
went on to work in the digital sector [27]. However, the COVID-19 crisis has exposed a widening digital divide; over the past few months, our planet has been pushed into a compulsory 'digital metamorphosis', a true collective experiment launched without a strategy or parachute [28]. The European Commission, the European Parliament and EU leaders agreed on a recovery plan that will lead the way out of the crisis and lay the foundations for a digital, greener and more sustainable Europe [29]. This is also a time during which citizens want to bridge digital divides and accelerate digital transformation, and three out of four Europeans think that there are 3 priority areas that need to be addressed—digital public services, digital skills and broadband internet access [30]. All of these factors lead us to believe that this is the right time to act even more decisively and bring best practices to the attention of the international community for widespread dissemination and to encourage the successful implementation of an integrated STEM program [31]. Among these, the Digital Girls summer camp stands out as a unique initiative, that is starting to garner positive results, specifically in terms of concretely reducing the gender gap in ICT. At the University of Modena and Reggio Emilia, where the camp has been running since 2014, the percentage of female students enrolled in the course of Computer Engineering has increased from almost 15\% in the academic year 2013/14, to over $20 \%$ in the last two years. This increase is particularly interesting if compared with the percentage of female students globally enrolled at the Department of Engineering (which includes several other courses in Engineering), for which the average share has remained at around $15 \%$ from 2014 to now.

\section{Conclusions}

In this paper, we described our experiences of organizing the summer camp Digital Girls. Due to the COVID-19 emergency, we have profoundly modified the 2020 edition of the summer camp, holding specific online activities as opposed to in past editions where activities were carried out in-presence. We have nevertheless maintained a well-integrated approach to provide opportunities for students to learn in more relevant and stimulating ways, to encourage the use of higher-level critical thinking skills, and to improve problemsolving skills. The results in this paper reveal an interesting comparison between the impacts of in-presence, pre-pandemic editions of the summer camp and the online version of Digital Girls formulated in response to the health emergency. This analysis can act as a valuable reference and inspiration for those who wish to replicate the effort within their communities to build the necessary parachute for the requirements of the digital transformation occurring throughout the world. In future, we plan to extend the initiative to other territories within our region through collaborations with other Universities and economic and political institutions; we believe that only the active collaboration of all stakeholders will help to redress the problem of the digital gender gap and mitigate the contextual factors that foster it.

Author Contributions: Conceptualization, A.C. and C.C.; methodology, C.C., F.F. and A.C.; software, F.F.; validation, M.C.; formal analysis, M.C.; investigation, A.C., C.C. and F.F.; data curation, F.F.; writing—original draft preparation, A.C., C.C. and F.F.; writing—review and editing, C.C. and A.C.; supervision, M.C. All authors have read and agreed to the published version of the manuscript.

Funding: This research received no external funding.

Institutional Review Board Statement: Not applicable.

Informed Consent Statement: Not applicable.

Data Availability Statement: Not applicable.

Conflicts of Interest: The authors declare no conflict of interest. 


\section{References}

1. European Commission. ICT for Work: Digital Skills in the Workplace, Report. March 2021. Available online: https://digitalstrategy.ec.europa.eu/en/library/ict-work-digital-skills-workplace (accessed on 31 October 2021).

2. European Commission. The Digital Economy and Society Index (DESI), Shaping Europe's Digital Future Report. 2020. Available online: https:/ / ec.europa.eu/digital-single-market/en/digital-economy-and-society-index-desi (accessed on 31 October 2021).

3. Eurostat, Girls and Women under-Represented in ICT, Eurostat Report. 2018. Available online: https:/ / ec.europa.eu/eurostat/ web / products-eurostat-news / - EDN-20180425-1 (accessed on 31 October 2021).

4. European Commission. Women in the Digital Age; DG Communications Networks, Content \& Technology: Luxemburg, 2018.

5. Mervis, J. They're Fun. But Can STEM Camps for Girls Really Make a Difference? Science, American Association for the Advancement of Science: Washington, DC, USA, 2018.

6. Breiner, J.M.; Harkness, S.S.; Johnson, C.C.; Koehler, C.M. What is STEM? A discussion about conceptions of STEM in education and partnerships. Sch. Sci. Math. 2012, 112, 3-11. [CrossRef]

7. Canali, C.; Addabbo, T.; Moumtzi, V. A best practice for attracting female students to enrol in ICT studies. In Proceedings of the 2nd Int. Conference on Gender Research (ICGR), Rome, Italy, 11-12 April 2019.

8. OECD. PISA 2015 Results (Volume I): Excellence and Equity in Education; PISA, OECD Publishing: Paris, France, 2016. [CrossRef]

9. Régner, I.; Steele, J.R.; Ambady, N.; Thinus-Blanc, C.; Huguet, P. Our future scientists: A review of stereotype threat in girls from early elementary school to middle school. Rev. Int. De Psychol. Soc. 2014, 27, 13-51.

10. OECD. Students, Computers and Learning: Making the Connection; PISA, OECD Publishing: Paris, France, 2015. [CrossRef]

11. Barker, L.J.; Aspray, W. The State of Research on Girls and IT, Women and Information Technology: Research on Underrepresentation; Cohoon, J.M., Aspray, W., Eds.; MIT Press: Cambridge, MA, USA, 2006; pp. 3-54.

12. Shin, J.E.L.; Levy, S.R.; London, B. Effects of role model exposure on STEM and non-STEM student engagement. J. Appl. Soc. Psychol. 2016, 46, 410-427. [CrossRef]

13. OECD. PISA results in focus. In Programme for International Students Assessment; OECD Publishing: Paris, France, 2015.

14. Davaki, K.; European Parliament, Policy Department for Citizen's Right and Constitutional Affairs. The Underlying Causes of the Digital Gender Gap and Possible Solutions for Enhanced Digital Inclusion of Women and Girls. 2018. Available online: http:/ / www.europarl.europa.eu/RegData/etudes/STUD/2018/604940/IPOL_STU(2018)604940_EN.pdf (accessed on 31 October 2021).

15. Talks, I.; Edvinsson, I.; Birchall, J. Programmed Out: The Gender Gap in Technology in Scandinavia; Plan International Norway: New York, NY, USA, 2019.

16. Faenza, F.; Canali, C.; Carbonaro, A. Evaluating different approaches to closing the gender gap at ICT summer camps in Italy. In Proceedings of the International Conference on Gender Research (ICGR), Aveiro, Portugal, 21-22 June 2021.

17. Faenza, F.; Canali, C.; Carbonaro, A. ICT Extra-Curricular Activities: The "Digital Girls" Case Study for the Development of Human Capital. In Proceedings of the International Research \& Innovation Forum, Athens, Greece, 7-9 April 2021.

18. Eurostat. International Standard Classification of Education (ISCED). 2016. Available online: https://ec.europa.eu/eurostat/ statistics-explained/index.php?title=International_Standard_Classification_of_Education_(ISCED) (accessed on 31 October 2021).

19. Eurostat. Students Enrolled in Tertiary Education by Education Level, Programme Orientation, Sex and Field of Education, European Commission Dataset Detail. 2019. Available online: https:/ / ec.europa.eu/eurostat/web/products-datasets/-/educ_ uoe_enrt03 (accessed on 31 October 2021).

20. Pollock, L.; McCoy, K.; Carberry, S.; Hundigopal, N.; You, X. Increasing high school girls self confidence and awareness of CS through a positive summer camp experience. In Proceedings of the 35th Symposium on Computer Science Education, Norfolk, VA, USA, 3-7 March 2004.

21. Main, J.B.; Schimpf, C. The underrepresentation of women in computing fields: A synthesis of literature using a life course perspective. IEEE Trans. Educ. 2017, 60, 296-304. [CrossRef]

22. Carbonaro, A.; Ravaioli, M. Peer assessment to promote deep learning and to reduce a gender gap in the traditional introductory programming course. J. e-Learn. Knowl. Soc. 2017, 13, 121-129.

23. Carbonaro, A. Improving web search and navigation using summarization process. In World Summit on Knowledge Society; Springer: Berlin/Heidelberg, Germany, 2010; pp. 131-138.

24. Murphy, A.; Kelly, B.; Bergmann, K.; Khaletskyy, K.; O'Connor, R.V.; Clarke, P.M. Examining unequal gender distribution in software engineering. In European Conference on Software Process Improvement; Springer: Berlin/Heidelberg, Germany, 2019; pp. 659-671.

25. Carbonaro, A. Good practices to influence engagement and learning outcomes on a traditional introductory programming course. Interact. Learn. Environ. 2019, 27, 919-926. [CrossRef]

26. Elena-Bucea, A.; Cruz-Jesus, F.; Oliveira, T.; Coelho, P.S. Assessing the role of age, education, gender and income on the digital divide: Evidence for the European Union. Inf. Syst. Front. 2020, 21, 1-15. [CrossRef]

27. Pladaitè, M.; Pypaert, P. Europe and North America, Agenda for Sustainable Development. 2021. Available online: https://unstats.un. org/sdgs/report/2021/The-Sustainable-Development-Goals-Report-2021.pdf (accessed on 31 October 2021).

28. Zheng, Y.; Walsham, G. Inequality of what? An intersectional approach to digital inequality under COVID-19. Inf. Organ. 2021, 31, 100341. [CrossRef] 
29. Rodríguez, P.M. 7. The Eu Budget: The New Mff and the Recovery Instrument: Next Generation Eu. 2021. Available online: https:/ / www.ieaf.es/images/Publicaciones-FEF/Anuarioeuro2021/10_The_EU_budget.pdf (accessed on 31 October 2021).

30. Rodriguez-Hevía, L.F.; Navío-Marco, J.; Ruiz-Gómez, L.M. Citizens' involvement in E-government in the European Union: The rising importance of the digital skills. Sustainability 2020, 12, 6807. [CrossRef]

31. Kelley, T.R.; Knowles, J.G. A conceptual framework for integrated STEM education. Int. J. STEM Educ. 2016, 3, 1-11. [CrossRef] 